OPEN ACCESS

Edited by:

Andrea lcks,

Heinrich Heine University of

Düsseldorf, Germany

Reviewed by:

Burkhard Haastert,

Independent Researcher, Neuenrade,

Germany

Christa Elisabeth Scheidt-Nave,

Robert Koch Institute, Germany

*Correspondence:

Sanet van Zyl

gnfssvz@ufs.ac.za

Specialty section:

This article was submitted to

Clinical Diabetes,

a section of the journal

Frontiers in Public Health

Received: 09 June 2020 Accepted: 15 September 2020

Published: 16 October 2020

Citation:

van Zyl S, van Rooyen FC, Joubert G, Kruger WH and Walsh CM (2020) A

Comparison of the

Socio-Behavioral-Metabolic Risk Profiles and Associated Factors for

Chronic Diseases of Lifestyle in Urban and Rural Communities in Central South Africa.

Front. Public Health 8:570676. doi: 10.3389/fpubh.2020.570676

\section{A Comparison of the Socio-Behavioral-Metabolic Risk Profiles and Associated Factors for Chronic Diseases of Lifestyle in Urban and Rural Communities in Central South Africa}

\author{
Sanet van Zyl ${ }^{1 *}$, Francios C. van Rooyen ${ }^{2}$, Gina Joubert ${ }^{2}$, Willem H. Kruger ${ }^{3}$ and \\ Corinna M. Walsh ${ }^{4}$
}

${ }^{1}$ Department of Basic Medical Sciences, Faculty of Health Sciences, University of the Free State, Bloemfontein, South Africa, ${ }^{2}$ Department of Biostatistics, Faculty of Health Sciences, University of the Free State, Bloemfontein, South Africa, ${ }^{3}$ Department of Community Health, Faculty of Health Sciences, University of the Free State, Bloemfontein, South Africa, ${ }^{4}$ Department of Nutrition and Dietetics, Faculty of Health Sciences, University of the Free State, Bloemfontein, South Africa

Background: The global escalating prevalence of lifestyle-related non-communicable diseases places a significant burden on health systems. Chronic diseases of lifestyle $(C D L)$ are a group of diseases that share similar modifiable risk factors that can result in long-term disease processes. Considering the socio-behavioral-metabolic risk profiles of communities and risk factors predictive of the presence of CDL can assist in the development of focused and effective community-based prevention, intervention, and treatment programs for CDL.

Aim: To determine the socio-behavioral-metabolic risk profiles and identify associated factors for the following CDL: obesity, cardiovascular disease, hypertension, and type 2 diabetes mellitus in rural and urban communities in central South Africa.

Methodology: This cross-sectional study included adults aged 25-65 years in the rural Southern Free State and urban Mangaung. Social determinants, behavioral and metabolic risk factors, and inflammatory biomarkers for CDL were determined.

Results: In total, 575 rural (mean age: 42 years; 71\% female) and 429 urban (mean age: 44 years; 76\% female) participants were included in the study. More than $20 \%$ of participants in both communities reported being previously diagnosed with cardiovascular diseases; with reported hypertension and diabetes mellitus more prevalent among rural participants. Insufficient intake of fruit and vegetables, alcohol use, and high blood pressure were among the top five risk factors in both communities. Physical inactivity ranked among the top two risk factors in the urban community; while alcohol and tobacco use was significantly higher in the rural community. Fibrinogen was the most prevalent inflammatory marker in both communities (32.9 rural vs. 48.3\% urban). High sensitivity $\mathrm{C}$-reactive protein ( $\mathrm{Hs}-\mathrm{CRP})$, only available for rural participants, was high with increased levels in more than $80 \%$ of participants. In both communities, 
being female, having high blood pressure and increased fibrinogen levels were associated with obesity.

Conclusion: This study illustrated the high prevalence of socio-behavioral-metabolic risk factors for $\mathrm{CDL}$, and identified similarities and distinct differences in the risk profiles of rural and urban communities. Considering the CDL risk profiles of communities can assist in prioritizing health needs and contribute to the development of tailor-made community-based primary health care prevention, intervention, and health promotion programs.

Keywords: non-communicable diseases (NCDs), chronic diseases of lifestyle (CDL), socio-behavioral-metabolic risk profiles, obesity, cardiovascular disease, hypertension, type 2 diabetes mellitus, community-based primary health care prevention

\section{INTRODUCTION}

Non-communicable diseases (NCDs), also called chronic diseases, are a group of conditions that account for millions of deaths globally each year (1). Current projections indicate a significant rise in NCDs among the ranks of the top 10 leading global causes of death by 2040 , with NCDs mortality projected to be the leading cause of death in the African region by $2030(2,3)$. The World Health Organization's (WHO) country-specific profiles for NCDs (3) illustrate the escalating prevalence of modifiable lifestyle/behavioral risk factors in South Africa, that can lead to physiological and metabolic changes (obesity, high blood pressure, hyperglycemia, and hyperlipidemia) and result in chronic diseases of lifestyle (CDL), including hypertension, chronic lung diseases, cancer, and diabetes.

An increasing number of studies show strong evidence of the integral role that socio-demographic or background risk factors play in the multifactorial etiology of CDL, especially in developing countries. Moving from the conventional biomedical approach, to a holistic biopsychosocial approach that considers socio-demographic determinants, such as population aging and growth, low levels of education, poverty, inequitable access to health care, rapid urbanization, and adoption of a more westernized lifestyle, is required to address the escalating burden of CDL (1, 4-6).

In recent years, attention has also shifted from focusing only on adult lifestyle-related risk factors as a cause for maintaining the risk cycle for $\mathrm{CDL}$ to adopting a lifecourse approach that acknowledges the influence of early life experiences on adult health and mortality. It has become clear that chronic low-grade systemic inflammation is the root cause of many chronic diseases with evidence proposing links between early adversity (e.g., an unfavorable early environment), impairment of immune status, and susceptibility to CDL later in life $(7,8)$. The chronic low-grade inflammatory state is characterized by increased levels of inflammatory biomarkers

Abbreviations: CDL, chronic diseases of lifestyle; CVD, cardiovascular disease; Hs-CRP, high sensitivity C-reactive protein; NCD, non-communicable disease; NDP, national development plan; PAL, physical activity level. that reflect inflammatory load, for example; high sensitivity Creactive protein (Hs-CRP), fibrinogen, high density lipoprotein (HDL), white blood cells (WBC), and cortisol (9-12). Lifestyle interventions, including exercise, healthy diet, and sleep patterns, managing stress and a focus on overall well-being, may have multiple anti-inflammatory effects, including favorable long-term changes in biomarkers of inflammation that may lower the risk of $\mathrm{CDL}(4,13)$. Health care professionals are encouraged to advocate for an anti-inflammatory lifestyle and purposefully address it at patient, community, and national levels to improve the health and well-being of populations (4).

The National Development Plan (NDP) 2015-2020 of the South African Department of Health, focuses on nine long-term health goals to improve the health and well-being of the South African population and to strengthen health systems (14). One of the envisioned goals is a significant reduction in the prevalence of chronic diseases in South Africa by 2030. Primary health care facilities are the first point of contact with health services. In South Africa, these facilities are dominated by lifestyle-related chronic diseases that create a significant burden on health systems, with hypertension and type 2 diabetes mellitus ranked first and fourth, respectively, on the list of the top 25 diagnoses made at primary health care facilities (15). Mayosi et al. (5) highlighted the escalating burden and emerging differences in CDL profiles in rural and urban communities in South Africa, and the need for improved community-based health promotion and care.

Assessing and understanding the health needs of different communities can contribute to focused, targeted primary health care prevention, intervention, and treatment programs for CDL in resource-constrained settings, and support the vision of the NDP to reduce the prevalence of chronic diseases in South Africa. Detailed information relating to the multifactorial risk profile and factors maintaining the risk cycle for $\mathrm{CDL}$ in rural and urban communities in the Free State, South Africa are still limited and therefore this study was envisioned. The study aimed to determine the socio-behavioral-metabolic risk profiles and inflammatory markers, and to identify clusters of associated risk factors for the following CDLs: obesity, cardiovascular disease (CVD), hypertension, and type 2 diabetes mellitus with CDL in rural and urban communities in the Free State. 


\section{METHODS}

\section{Study Design, Population, and Sampling}

This cross-sectional epidemiological study formed part of the "Assuring Health for All" in the Free State (AHA FS) research study that investigated how living in rural and urban areas affects a person's lifestyle, health, and well-being. The study was conducted in two community service delivery sites of the University of the Free State. The rural part of the study was conducted in the southern Free State district of Xhariep in the rural towns of Springfontein, Trompsburg, and Phillippolis that form part of the service area of the Free State Rural Development Partnership Programme (FSRDPP). Adult members, aged 25 to 64 years, from households (formal plots and squatter households) in surrounding township areas of the three rural towns were eligible to participate in the study. Trained field workers visited all eligible households in these areas to explain the purpose of the study and recruit participants for the study. The urban part of the study was conducted in the service area of the Mangaung University Community Partnership Programme (MUCPP) clinic and a stratified proportional cluster sample of the communities in this service area was selected for the study. After determining the number of plots in the MUCPP service area using a municipal map a stratified proportional cluster sample, stratified by area and formal plots and squatter households in open areas, were done. After selecting $\mathrm{X}$ and $\mathrm{Y}$ coordinates randomly, 100 starting points were selected and from each starting point five adjacent households were approached by field workers and informed about the study. In each household all adult household members (25-64 years) were eligible to participate in the study. Trained field workers visited all eligible households to explain the purpose of the study and recruit participants for the study.

\section{Data Collection Procedures and Laboratory Analysis}

Data collection took place in community halls in the three rural towns of the Free State for the rural part of the study and in the MUCPP clinic for the urban part of the study. All participants were interviewed to complete questionnaires related to household socio-demographic, individual health, physical activity, and diet information. Language interpreters for Sesotho, Setswana, and isiXhosa-speaking participants assisted the researcher, where necessary. Senior dietetic students, under the supervision of lecturers from the Department of Nutrition and Dietetics at the University of the Free State (UFS), interviewed the participants and completed the questionnaires that focused on household socio-demographic information (e.g., age, gender, level of education, employment status, experienced stress) and health information that included lifestyle-related risk factors, family, and medication history.

Assessment of physical activity included a 24-h recall of all physical activities performed during the previous day, which included information on the time spent doing vigorous physical activity, moderate physical activity, walking activity, and sedentary periods. Frequency of activities that was not undertaken every day (e.g., gardening) was also determined. Using this information, the researchers calculated the physical activity level (PAL) for each participant, which were classified as: sedentary 1-1.39 PAL, low activity 1.4-1.59 PAL, active 1.6-1.89 PAL, and very active 1.9-2.5 PAL (16).

Anthropometric measurements were taken according to standard WHO procedures and included weight in kilograms $(\mathrm{kg})$, height in centimeters $(\mathrm{cm})$, and waist circumference $(\mathrm{cm})$. Weight was determined using a Seca ${ }^{\circledR}$ (Germany) digital electronic foot scale, with participants in examination gowns, without shoes. Anthropometric indices included body mass index (BMI) (weight in [kg] divided by the square of the standing height $\left.\left[\mathrm{m}^{2}\right]\right)$, with overweight classified as a BMI $\geq 25 \mathrm{~kg} / \mathrm{m}^{2}$ and obesity a BMI of $\geq 30 \mathrm{~kg} / \mathrm{m}^{2}$ (17). The cut-off point for central obesity was a waist circumference of $\geq 88 \mathrm{~cm}$ in women and $\geq 102 \mathrm{~cm}$ in men (18).

In addition to anthropometric assessment, medical examinations were conducted by qualified medical professionals from the Department of Basic Medical Sciences of the Faculty of Health Sciences, UFS. Participants with urgent medical conditions were referred on the day of the medical examination, and participants could obtain results of biochemical tests and referral letters (where necessary) during follow-up visits. Blood pressure was measured during the clinical examination in the supine position with a DS-175, auto-inflate electronic blood pressure monitor (Nissei, Japan). Hypertension was defined as a systolic blood pressure of $140 \mathrm{mmHg}$ or higher and/or a diastolic pressure of $90 \mathrm{mmHg}$ or higher (19).

Fasting blood samples were obtained to determine biomedical risk factors as well as inflammatory markers. All analyses were performed by an accredited laboratory. Serum and plasma samples were prepared in the laboratory according to standard methods and stored at $-80^{\circ} \mathrm{C}$ until analyses were performed. Complete full blood counts were performed using the Roche Sysmex XT 2000i analyzer ${ }^{\circledR}$ (Sysmex Sverige, Kungsbacka, Telefon). Blood specimens for the measurement of fasting venous plasma glucose were drawn into fluoride tubes. Samples were centrifuged within $4 \mathrm{~h}$ and fasting venous plasma glucose was measured using the glucose oxidase method on a Beckman LX20 ${ }^{\circledR}$ auto-analyzer (Beckman Coulter, Fullerton, CA. Diabetes mellitus was defined as fasting plasma glucose value $\geq 7.0$ $\mathrm{mmol} / \mathrm{L}[126 \mathrm{mg} / \mathrm{dl}]$ and HbAlc levels were defined as prediabetes: $5.7-6.4 \%(39-47 \mathrm{mmol} / \mathrm{mol})$ and diabetes: $6.5 \%$ or higher (48 mmol/mol or higher) $(20,21)$.

Fasting serum lipid levels were measured using enzymatic assay kits on a Beckman LX20 ${ }^{\circledR}$ auto-analyzer (Beckman Coulter, Fullerton, CA). Raised blood lipids were defined as total cholesterol $\geq 200 \mathrm{mg} / \mathrm{dl}$ ( $5.2 \mathrm{mmol} / \mathrm{l})$; low-density lipoprotein (LDL) cholesterol $\geq 100 \mathrm{mg} / \mathrm{dl}(2.59 \mathrm{mmol} / \mathrm{L})$; triglycerides $\geq 150 \mathrm{mg} / \mathrm{dl}(1.7 \mathrm{mmol} / \mathrm{L})$. Hs-CRP results were categorized as low risk: $<1.0 \mathrm{mg} / \mathrm{L}$, average risk $(1.0-3.0 \mathrm{mg} / \mathrm{L})$ or high risk (>3.0 mg/L) levels, as indicated by the American Heart Association and US Centers for Disease Control and Prevention recommendations (22). Raised total leucocytes was defined as $\geq 9.88 \times 10^{9} / \mathrm{L}$; fibrinogen $\geq 290 \mathrm{mg} / \mathrm{dl}$. The ratio of NLR was determined with normal value ranging between 0.78 and $3.53(23,24)$. 


\section{Statistical Analysis}

Data were statistically analyzed by the Department of Biostatistics, UFS, using frequencies and percentages for categorical variables and means for numerical variables. Comparisons between rural and urban participants were done using contingency tables with chi-squared or Fisher's exact tests as appropriate. A level of significance was accepted as a two-tailed $P$-value $<0.05$.

To identify factors for CDL, logistic regression models with each potential risk factor, age, and gender were fitted. Risk factors with $P$-value $<0.15$ were included in the stepwise logistic regression models to identify significant associated risk factors. Stepwise logistic regression starting with all variables included in the model (i.e., backward elimination) was performed, using $P=0.05$ as threshold for entry and exit. If a variable with multiple missings was not significant in the model, the model was run again excluding that variable. Odds ratios (OR) and 95\% confidence intervals (95\% CI) were used to present risk factors identified through this process for the following: CDL; obesity, hypertension, diabetes, and CVDs. Obesity was defined as a BMI of $\geq 30 \mathrm{~kg} / \mathrm{m}^{2}$; hypertension as systolic blood pressure $\geq 140 \mathrm{mmHg}$ and/or diastolic blood pressure $\geq 90 \mathrm{mmHg}$ ) or on medication to lower blood pressure; and diabetes mellitus as fasting plasma glucose value $\geq 7.0 \mathrm{mmol} / \mathrm{L}$ or with a history of diagnosis of diabetes. Reported history of CVDs included stroke, heart disease, angina, heart attack, and heart failure.

The socio-behavioral-metabolic risk factors and inflammatory biomarkers categorized and defined below were considered for inclusion in the univariate logistic regression models. Variables which were significant in the different models were selected and considered for the final multivariate logistic regression models.

Behavioral risk factors were defined as:

Physically inactivity (level 1: sedentary- $<60$ min of moderate to vigorous-intensity activity daily, and level 2: low activity$<150$ min of moderate-intensity activity per week); unhealthy diet (insufficient intake of fruit and vegetables/low consumption of fruits and vegetables defined as a consumption of $<5$ total servings [ $400 \mathrm{~g}$ ] of fruit and vegetables per day); tobacco use (currently smoke and formerly smoked); alcohol use (currently and formerly used).

Metabolic risk factors with categorical cut points were defined as follows:

Raised blood glucose (fasting plasma glucose value $\geq 7.0$ $\mathrm{mmol} / \mathrm{L}$ [126 mg/dl]); HbAlc (diabetic: $6.5 \%$ or higher [48 $\mathrm{mmol} / \mathrm{mol}$ or higher]); high blood pressure (elevated systolic blood pressure $\geq 140 \mathrm{mmHg}$ and/or diastolic blood pressure $\geq 90 \mathrm{mmHg}$ ); overweight $\left(\mathrm{BMI} \geq 25 \mathrm{~kg} / \mathrm{m}^{2}\right.$ ) and obesity $\left(\geq 30 \mathrm{~kg} / \mathrm{m}^{2}\right)$; increased waist circumference (men $\geq 102 \mathrm{~cm}$ [high risk]; women $\geq 88 \mathrm{~cm}$ [high risk]); raised blood lipids (total cholesterol $\geq 200 \mathrm{mg} / \mathrm{dl}$ [5.2 mmol/L]); LDL cholesterol $\geq 100 \mathrm{mg} / \mathrm{dl}(2.59 \mathrm{mmol} / \mathrm{L})$; triglycerides $\geq 150 \mathrm{mg} / \mathrm{dl}$ (1.7 mmol/L).

Inflammatory biomarkers with categorical cut points were defined as follows:

Hs-CRP: average risk (1.0-3.0 mg/L) or high risk (>3.0 mg/L); total leucocytes $\left(>9.88 \times 10^{9} / \mathrm{L}\right) ; \mathrm{NLR} \geq 3.35$; fibrinogen $\geq$ $290 \mathrm{mg} / \mathrm{dl}$.

\section{Ethical Considerations}

Ethics approval to conduct the AHA-FS study was obtained from the Ethics Committee of the Faculty of Health Sciences (UFSETOVS number 21/07), the Health Sciences Research Ethics Committee (HSREC) of UFS (UFS-HSD2017/1435), the Free State Department of Health and local municipalities before commencement of the study. In all communities, trained field workers recruited participants during home visits and the research team explained the project to participants before written informed consent was obtained from each participant.

\section{RESULTS}

\section{Study Population}

A total number of 1,004 (575 rural and 429 urban) participants, between 25 and 65 years adhered to the study criteria and were included in the study. The mean age of the rural and urban participants was 47.2 years ( $71 \%$ females) and 44.4 years $(76 \%$ females), respectively.

\section{Socio-Demographic Characteristics and Background Risk Factors of Study Participants}

Results obtained through socio-demographic questionnaires, summarized in Table 1, revealed that a higher percentage of urban (19.9) vs. rural (15.4\%) participants completed grade 1112 at school level. Reported unemployment status was higher in the urban community $(54.8 \%)$ than the rural community (24.2\%). While $31.0 \%$ of urban participants reported that they experienced permanent stress, only $9.0 \%$ of rural participants reported similar levels of stress. Results obtained through individual health questionnaires are summarized in Table 1, indicated the high prevalence of hypertension, diabetes mellitus, and CDVs among rural and urban participants and their family members.

A large percentage of rural and urban participants (63.1 and $48.2 \%$, respectively) reported having hypertension themselves, with just over $60 \%$ of participants in both study groups reporting a family history of hypertension. Self-reported diabetes mellitus was higher in the rural than urban (11.0 vs. $7.4 \%)$ participants, with more than a quarter of participants (26.0 rural and $33.1 \%$ urban) reporting a family history of diabetes mellitus. Twenty-four percent and $26.7 \%$ of rural and urban participants, respectively, reported being previously diagnosed with CVDs (stroke, heart disease, angina, heart attack and heart failure) and a high reported family history was also observed among both study populations (rural 41.3 and urban 52.1\%).

The high prevalence of behavioral and metabolic risk factors among the rural and urban study populations are illustrated in Table 2. Significant differences between rural and urban participants were observed in tobacco use $(P<0.01)$, alcohol use $(P<0.01)$, PAL $(P<0.01)$, total cholesterol levels $(P<0.01)$, and high blood pressure $(P<0.01)$. The different behavioral and metabolic risk factors were ranked, and Table 3 illustrates distinct differences between the risk profiles of rural and urban communities. Insufficient intake of fruit and vegetables was the 
TABLE 1 | Reported socio-demographic/background risk factors of rural and urban participants.

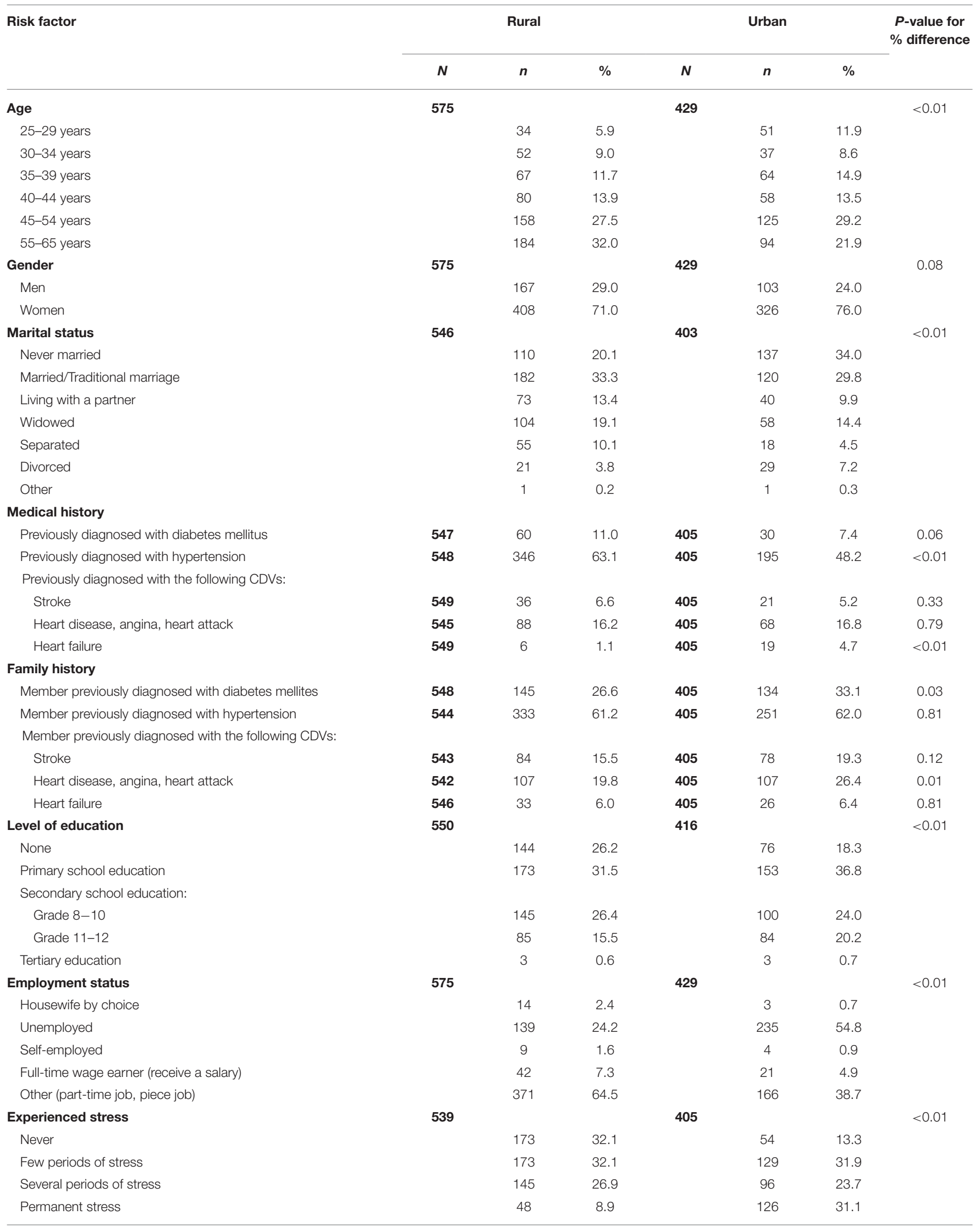

CDV, cardiovascular disease; $N$, number of participants. 
TABLE 2 | Summary of behavioral, metabolic and inflammatory risk factors of rural and urban participants.

\begin{tabular}{|c|c|c|c|c|c|c|c|c|}
\hline \multirow[t]{3}{*}{ Risk factor } & \multirow[t]{3}{*}{ Parameter } & \multicolumn{3}{|c|}{ Rural } & \multicolumn{3}{|c|}{ Urban } & \multirow[t]{3}{*}{$P$-value for $\%$ difference } \\
\hline & & $N$ & $n$ & $\%$ & $N$ & $n$ & $\%$ & \\
\hline & & 575 & & & 429 & & & \\
\hline \multicolumn{9}{|l|}{ BEHAVIORAL RISK FACTORS } \\
\hline Tobacco use & Currently smoke \& formerly smoked & 548 & 322 & 58.8 & 405 & 130 & 32.1 & $<0.01$ \\
\hline Insufficient intake of fruit and vegetables & $\begin{array}{l}\text { Consumption }<5 \text { servings }(400 \mathrm{~g} \text { ) of fruit and } \\
\text { vegetables per day }\end{array}$ & 550 & 530 & 96.4 & 418 & 410 & 98.1 & 0.11 \\
\hline Alcohol use & Currently intake and formerly used & 546 & 437 & 80.0 & 404 & 219 & 54.2 & $<0.01$ \\
\hline Physical inactivity & $\begin{array}{l}\text { Level } 1 \text { (i.e., sedentary: <60 min of moderate to } \\
\text { vigorous-intensity activity daily) and Level } 2 \\
\text { (i.e., low activity: }<150 \text { min of } \\
\text { moderate-intensity activity per week) }\end{array}$ & 550 & 150 & 27.3 & 415 & 276 & 66.5 & $<0.01$ \\
\hline \multicolumn{9}{|l|}{ METABOLIC RISK FACTORS } \\
\hline Elevated blood lipids (total cholesterol) & High risk: $\geq 240 \mathrm{mg} / \mathrm{dl}(\geq 6.22 \mathrm{mmol} / \mathrm{L})$ & 552 & 75 & 14.2 & 415 & 17 & 4.1 & $<0.01$ \\
\hline High blood glucose & $\geq 7.0 \mathrm{mmol} / \mathrm{L}(126 \mathrm{mg} / \mathrm{dl})$ & 544 & 43 & 7.9 & 411 & 18 & 4.4 & 0.03 \\
\hline $\mathrm{HbA1c}$ & $\begin{array}{l}\text { Diabetes: } 6.5 \% \text { or higher }(48 \mathrm{mmol} / \mathrm{mol} \text { or } \\
\text { higher) }\end{array}$ & 548 & 53 & 9.7 & 415 & 25 & 6.0 & 0.04 \\
\hline High blood pressure & $\begin{array}{l}\text { Systolic blood pressure of } 140 \mathrm{mmHg} \text { or higher } \\
\text { and/or a diastolic pressure of } 90 \mathrm{mmHg} \text { or } \\
\text { higher }\end{array}$ & 563 & 382 & 67.9 & 413 & 235 & 56.9 & $<0.01$ \\
\hline Body mass index & Overweight and obese $\mathrm{BMI} \geq 25.00$ & 555 & 295 & 53.2 & 419 & 227 & 54.2 & 0.75 \\
\hline Waist circumference & $\begin{array}{l}\text { Men } \geq 102 \mathrm{~cm} \text { (high risk)/Women } \geq 88 \mathrm{~cm} \text { (high } \\
\text { risk) }\end{array}$ & 547 & 323 & 59.1 & 418 & 223 & 53.4 & 0.08 \\
\hline \multicolumn{9}{|l|}{ INFLAMMATORY RISK FACTORS } \\
\hline Total leucocytes & $\left(>9.88 \times 10^{9} / L\right)$ & 543 & 71 & 13.1 & 417 & 18 & 4.3 & $<0.01$ \\
\hline Neutrophils & $\left(>7.5 \times 10^{9} / \mathrm{L}\right)$ & 544 & 25 & 4.6 & 417 & 6 & 1.4 & 0.01 \\
\hline Lymphocytes & $\left(>4.0 \times 10^{9} / \mathrm{L}\right)$ & 544 & 4 & 7.7 & 417 & 7 & 1.7 & $<0.01$ \\
\hline Monocytes & $\left(>1.8 \times 10^{9} / \mathrm{L}\right)$ & 543 & 35 & 6.5 & 417 & 25 & 6.0 & 0.78 \\
\hline Neutrophil:lymphocyte ratio & $\geq 3.53$ & 543 & 29 & 5.3 & 417 & 17 & 4.1 & 0.36 \\
\hline Fibrinogen & $\geq 290 \mathrm{mg} / \mathrm{dl}$ & 520 & 171 & 32.9 & 389 & 188 & 48.3 & $<0.01$ \\
\hline
\end{tabular}

leading risk factor in both communities. Tobacco and alcohol use ranked higher in the rural community. Physical inactivity ranked among the top two risk factors in the urban community followed by high blood pressure. More than half of participants in both communities were either overweight or obese.

The number of risk factors in the two populations were calculated and illustrated in Figure 1. Due to the presence of missing information it was decided to include all participants with information for seven or more of the 10 behavioral and metabolic risk factors in the calculations. Of the 575 rural participants, the data of 561 were included and of the 429 urban participants, the data of 420 were included (Table 3). For participants with information for 7, 8 or 9 of the risk factors, the number of risk factors present were calculated proportional to the number of risk factors with known information and rounded down to a value between 0 and 10. For example 1 risk factor present out of 7 with known information was calculated as $1 / 7^{*} 10=1.4$ and reported as 1 .

Markers of inflammation are summarized in Table 2. Hs-CRP results (average risk: $1.0-3.0 \mathrm{mg} / \mathrm{L}$ and high risk: $>3.0 \mathrm{mg} / \mathrm{L}$ ) were only available for rural participants, with average and high levels observed in $88.5 \%$ of rural participants. Fibrinogen was the most prevalent inflammatory marker in both communities with $32.9 \%$ of rural participants and $48.3 \%$ of urban participants having elevated levels. Significant differences for total leucocytes $(P<0.01)$, lymphocytes $(P<0.01)$, and fibrinogen $(P<0.01)$ were observed between rural and urban participants, with more rural participants presenting with elevated leucocytes (13.1 rural vs. $4.3 \%$ urban) and lymphocytes (7.7 rural vs. $1.7 \%$ urban) and more urban participants with elevated fibrinogen. The least prevalent inflammatory marker in both communities was elevated neutrophils (4.6 rural vs. $1.4 \%$ urban).

In addition to the comparison of the socio-behavioralmetabolic risk factors and inflammatory biomarkers for CDL in rural and urban participants, univariate analysis was performed to identify risk factors associated with obesity, hypertension, diabetes, and CVDs, results are illustrated in Table 4. The number of participants excluded due to missing values include 20 rural and 17 urban participants for obesity, 9 rural and 7 urban participants for hypertension, 29 rural and 17 
TABLE 3 | Ranked behavioral and metabolic risk factors of rural and urban participants.

\begin{tabular}{|c|c|c|c|c|}
\hline Rural & Percentage (\%) & Ranking & Percentage (\%) & Urban \\
\hline Insufficient intake of fruit and vegetables & 96.4 & 1 & 98.1 & Insufficient intake of fruit and vegetables \\
\hline Alcohol use & 80.0 & 2 & 66.5 & Physical inactivity \\
\hline High blood pressure & 67.9 & 3 & 56.9 & High blood pressure \\
\hline Increased waist circumference & 59.1 & 4 & 54.2 & Alcohol use \\
\hline Tobacco use & 58.8 & 5 & 54.2 & Body mass index \\
\hline Body mass index & 53.2 & 6 & 53.4 & Increased waist circumference \\
\hline Physical inactivity & 27.3 & 7 & 32.1 & Tobacco use \\
\hline Elevated blood lipid levels & 14.2 & 8 & 6.0 & Elevated HbA1c levels \\
\hline Elevated $\mathrm{HbA} 1 \mathrm{c}$ levels & 9.7 & 9 & 4.4 & Elevated blood glucose levels \\
\hline Elevated blood glucose levels & 7.9 & 10 & 4.1 & Elevated blood lipid levels \\
\hline
\end{tabular}

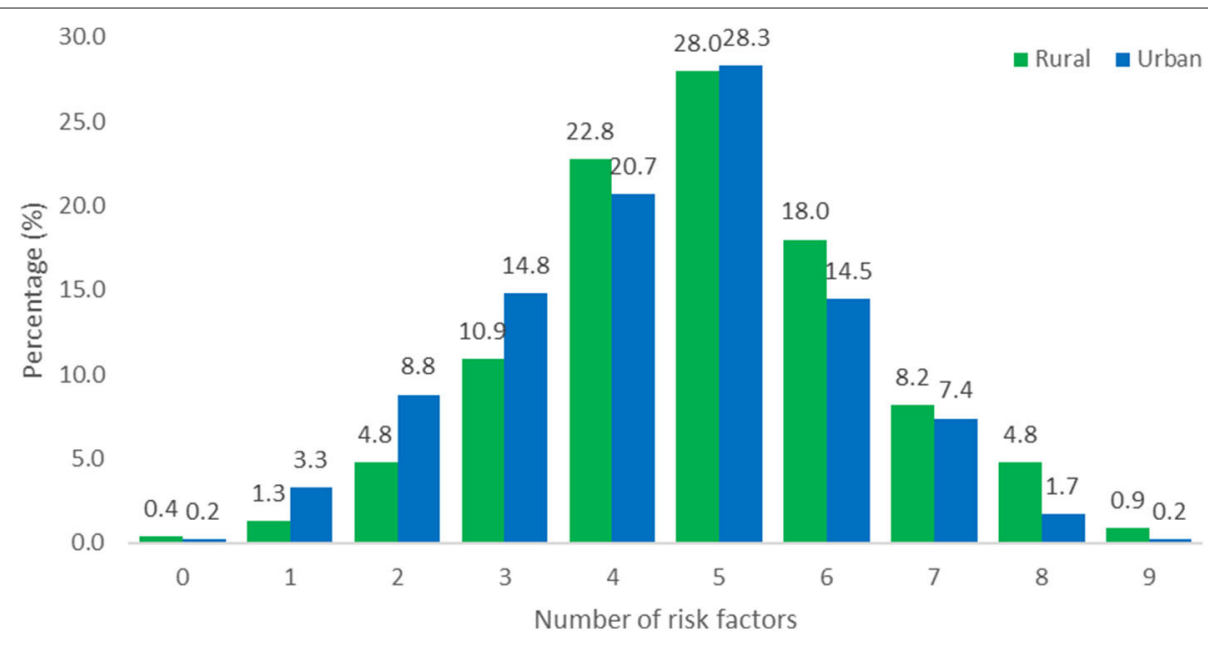

FIGURE 1 | Total number of behavioral and metabolic risk factors for rural $(N=561)$ and urban $(N=420)$ participants. The data of 14 rural participants and 9 urban participants were incomplete.

urban for diabetes, 26 rural and 24 urban participants for cardiovascular disease.

Results of the multivariate logistic regression models are indicated in Table 5.

Multivariate logistic regression analysis showed that in the rural sample, being female, having high blood pressure, increased triglycerides, and increased levels of the inflammatory biomarkers Hs-CRP and fibrinogen were positively associated with obesity. In the urban sample, being female, having high blood pressure, high blood glucose, and fibrinogen levels were positively associated with being obese. As expected, smoking was negatively associated with obesity in rural (OR $0.25 ; \quad P<0.01$ ) and urban (OR 0.42; $P<0.01$ ). Age advancement was associated with the presence of hypertension in both rural and urban areas. The probability of having hypertension in the rural area was higher with increased reported stress levels, while high HbAlc levels increased the odds of having hypertension 10.40 (95\% CI 1.37;78.98) times. In this sample, residing in an urban area, being overweight and obese were positively associated with the presence of hypertension.
In this study, adults living in an urban area had increased odds of diabetes mellitus with increased age; while increased waist circumference was positively associated with diabetes mellitus in rural (OR 4.10; $P<0.01$ ) areas. Based on the OR, adults living in a rural area, with a sedentary/low activity lifestyle, increased triglycerides, and leucocytes had increased odds of having diabetes. Adults residing in a rural area, with no education were almost three times (OR 2.9, 95\% CI 1.34; 6.30) more likely to have CVDs; in terms of the association between CVD and levels of stress, results were unexpected. Possible reasons for this will be included in the discussion. Urban participants with hypertension (OR 2.84, 95\% CI 1.39; 5.78), elevated glucose (OR 2.24, 95\% CI 1.03 ; 4.88), and leucocytes (OR 3.17, 95\% CI 1.09; 9.21) were more likely to have CVDs.

\section{DISCUSSION}

Statistics South Africa (Stats SA) has reported an increase in deaths due to cardiovascular diseases since 2009 in South Africa, with the highest percentage of these deaths (57.4\%) observed in 2016 (25). At that time, hypertension (ranked third), 
TABLE 4 | Significance of individual risk factors for chronic diseases of lifestyle (CDL).

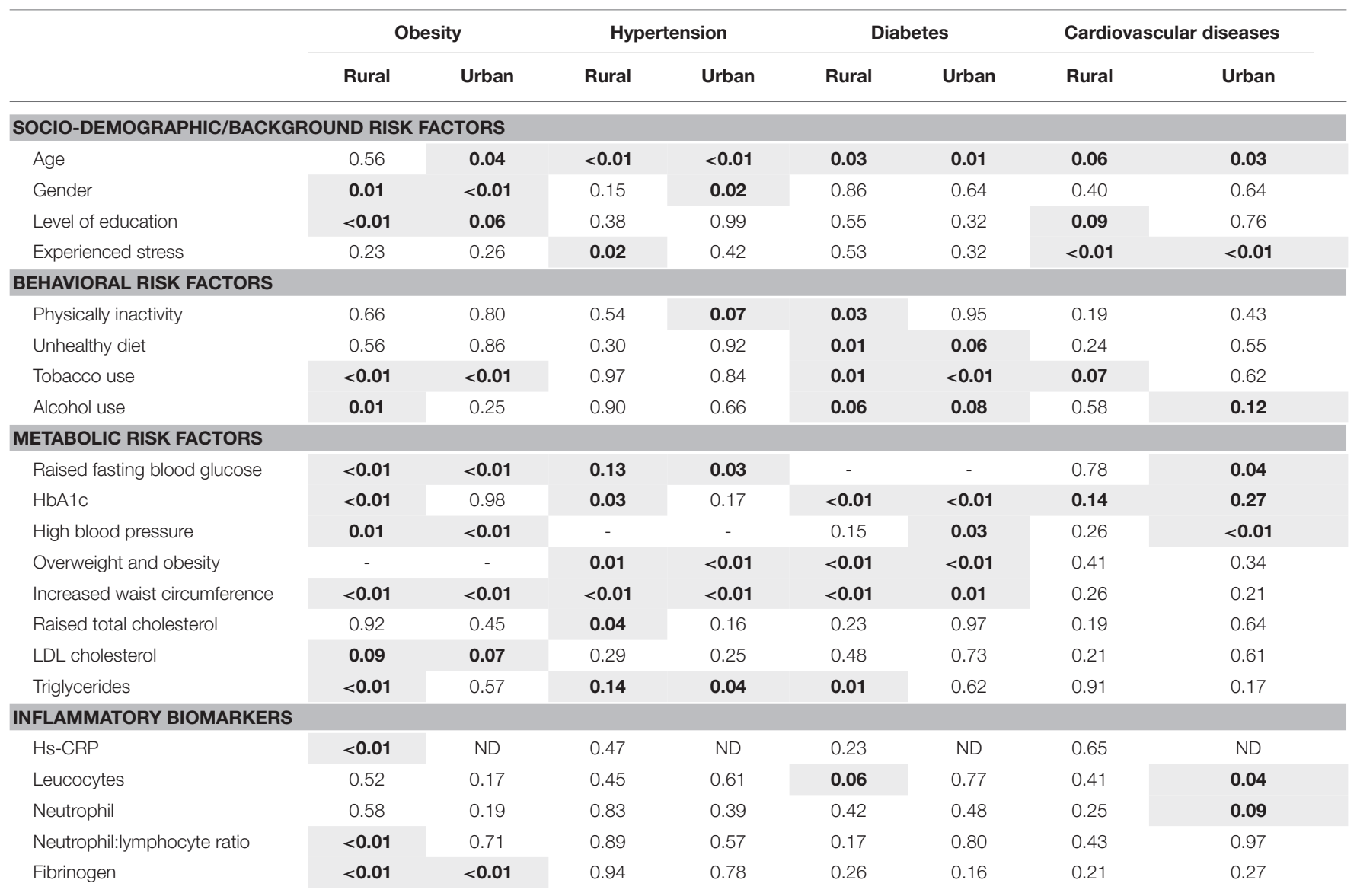

Risk factors with $p$-value $<0.15$ were included in the stepwise logistic regression models to identify significant ( $p$-value $<0.05)$ associated risk factors as displayed in Table 5 . Note missing values: Obesity (rural 20, urban 17); Hypertension (rural 9, urban 7), Diabetes (rural 29, urban 17), Cardiovascular disease (rural 26, urban 24).

ND, not done.

cerebrovascular disease (fourth), and diabetes mellitus (fifth) were among the 10 leading underlying natural causes of death in the Free State province. The social determinants of health and diseases cannot be ignored when looking at the mentioned deaths as studies concluded that the risk factors included several societal factors $(26,27)$. Identifying and addressing the major social determinants of health, forms an integral part of the South African National Department of Health's Primary Health Care Re-engineering Strategy (28). This study observed distinct differences between social determinants of CDL in rural and urban communities in the Free State. Although a higher percentage of urban participants had completed secondary school education, reported unemployment status was higher in the urban study population (54.8\%) than in the rural group (24.2\%). Almost a third of urban participants vs. 9\% of rural participants reported that they experienced permanent stress which may be related to unemployment status.

The high prevalence of reported cardio-metabolic diseases among rural and urban participants and their family members in this study illustrated the intra- and intergenerational burden of CDL in these communities. Although prevalence of chronic diseases was high in both groups, a higher percentage of rural participants reported being diagnosed with hypertension and diabetes. The findings of the present study are supported by those reported in the South African National Health and Nutrition Examination Survey (SANHANES) by Shisana et al. (29), who showed that at that time the Free State province had the highest prevalence of self-reported high blood pressure (45.8\%), high blood sugar $(26.7 \%)$, heart disease $(28.7 \%)$, and stroke $(14.5 \%)$, with an increase in self-reported high blood pressure and stroke observed between 2003 and 2012. The findings of the current study further highlight important urban and rural differences.

A study undertaken among older adults from 2007 to 2010 in six low- and middle-income countries (China, Ghana, India, Mexico, Russian Federation and South Africa) by Wu et al. (30) ranked seven risk factors for CDL (inadequate vegetable and fruit intake, low PALs, smoking, frequent alcohol use, high blood pressure, obesity, central obesity) and revealed that South Africa had the highest prevalence for low PALs (59.7\%) and obesity (45.2\%) across the six countries. Similarly, the present study revealed that insufficient intake of fruit and vegetables was the leading risk factor for CDL in both the urban and rural study populations. The high prevalence of food insecurity in the study population may have been responsible for this, with 73.2 
TABLE 5 | Significant socio-behavioral-metabolic risk factors, inflammatory biomarkers associated with the presence of obesity, cardiovascular disease, hypertension, and diabetes mellitus in a rural and urban sample.

\begin{tabular}{|c|c|c|c|c|c|}
\hline \multicolumn{2}{|c|}{ Variables } & \multicolumn{2}{|c|}{ Rural } & \multicolumn{2}{|c|}{ Urban } \\
\hline \multicolumn{6}{|l|}{ OBESITY } \\
\hline Sex & Female vs. male & 3.90 [2.35;6.48] & $<0.01$ & 8.64 [4.14;18.04] & $<0.01$ \\
\hline High blood glucose levels & Yes vs. No & & & $3.41[1.27 ; 9.13]$ & 0.02 \\
\hline Elevated triglycerides & Yes vs. No & $2.95[1.86 ; 4.66]$ & $<0.01$ & & \\
\hline $\begin{array}{l}\text { Average/high-risk } \\
\text { Hs-CRP }\end{array}$ & Yes vs. No & $2.59[1.20 ; 5.60]$ & 0.02 & & \\
\hline Elevated fibrinogen & Yes vs. No & $2.04[1.28 ; 3.24]$ & $<0.01$ & $2.11[1.27 ; 3.49]$ & $<0.01$ \\
\hline Stress & Never vs. permanent stress & $0.27[0.08 ; 0.95]$ & $<0.01$ & & \\
\hline Stress & $\begin{array}{l}\text { Few periods of stress vs. } \\
\text { permanent stress }\end{array}$ & $0.40[0.11 ; 1.44]$ & 0.21 & & \\
\hline Stress & $\begin{array}{l}\text { Several periods of stress vs. } \\
\text { permanent stress }\end{array}$ & $0.77[0.21 ; 2.88]$ & 0.18 & & \\
\hline $\mathrm{BMI}$ & & & & $2.19[1.08 ; 4.41]$ & 0.03 \\
\hline Waist circumference & & & & $2.44[1.22 ; 4.90]$ & 0.01 \\
\hline $\mathrm{HbA1c}$ & Diabetes (Yes vs. No) & $10.40[1.37 ; 78.98]$ & 0.02 & & \\
\hline \multicolumn{6}{|l|}{ DIABETES } \\
\hline Age(years) & $55-65$ vs. $25-34$ & & & 8.84 [1.92;40.66] & $<0.01$ \\
\hline Elevated leucocytes & Yes vs. No & $2.33[1.15 ; 4.67]$ & 0.02 & & \\
\hline \multicolumn{6}{|c|}{ CARDIOVASCULAR DISEASES } \\
\hline Stress & Never vs. permanent stress & $1.90[0.88 ; 4.11]$ & 0.05 & $0.75[0.31 ; 1.82]$ & 0.86 \\
\hline Stress & $\begin{array}{l}\text { Few periods of stress vs. } \\
\text { permanent stress }\end{array}$ & $2.14[0.98 ; 4.67]$ & 0.01 & $0.30[0.13 ; 0.66]$ & $<0.01$ \\
\hline Stress & $\begin{array}{l}\text { Several periods of stress vs. } \\
\text { permanent stress }\end{array}$ & $0.74[0.35 ; 1.56]$ & $<0.01$ & $1.75[0.93 ; 3.30]$ & $<0.01$ \\
\hline Education & None vs. tertiary education & $2.91[1.34 ; 6.30]$ & 0.04 & & \\
\hline Education & $\begin{array}{l}\text { Primary school } \\
\text { vs. tertiary education }\end{array}$ & $2.03[1.12 ; 3.67]$ & 0.31 & & \\
\hline Education & $\begin{array}{l}\text { Grade 8-12 vs. tertiary } \\
\text { education }\end{array}$ & $1.24[0.73 ; 2.11]$ & 0.12 & & \\
\hline High blood pressure & & & & $2.84[1.39 ; 5.78]$ & $<0.01$ \\
\hline Glucose levels & Diabetes (Yes vs. No) & & & $2.24[1.03 ; 4.88]$ & 0.04 \\
\hline Elevated leucocytes & Yes vs. No & & & $3.17[1.09 ; 9.21]$ & 0.03 \\
\hline
\end{tabular}

${ }^{*} P<0.05$.

Note missing values:

Obesity: 85 rural and 57 urban observations were excluded due to missing values for the response or explanatory variables Hypertension: 50 rural and 8 urban observations were excluded due to missing values for the response or explanatory variables.

Diabetes: 66 rural and 19 urban observations were excluded due to missing values for the response or explanatory variables.

Cardiovascular diseases: 31 rural and 17 urban observations were excluded due to missing values for the response or explanatory variables. 
and $87.4 \%$ of the current rural and urban families, respectively, classified as having a high risk of food insecurity (31). Low intake of fruits and vegetables has been reported in other South African studies, such as in a rural Limpopo community, where Maimela et al. (32) reported that $88.6 \%$ of participants had a low daily intake of fruit and vegetables. A contributing factor for this observation in our rural study population could be the distances that these participants need to travel on foot to purchase fruit and vegetables ( 83 rural vs. $54 \%$ urban) (31). In addition, the transition to an unhealthier "Westernized" diet in South Africa is often characterized by low intake of fresh fruit and vegetables $(33,34)$.

As confirmed in the current study, urban dwellers are more likely to experience a sedentary lifestyle with decreased PALs (35). Physical inactivity was ranked among the top two risk factors for CDL in our urban community (66.5\%) and ranked seventh $(27.3 \%)$ in the rural community. Several studies have illustrated an inverse relationship between physical activity and the prevalence of CDL such as hypertension and diabetes mellitus (29), while regular physical activity has been shown to strengthen resilience to stress.

The SANHANES (29) found that $50.4 \%$ of Free State participants smoked tobacco in 2012; this is much higher than the national average of $32.8 \%$. In the current study, significant differences were observed between tobacco use of urban and rural participants ( 58.8 vs. $32.1 \%$; $P<0.01$ ). Tobacco use ranked among the top five risk factors in the rural community but ranked much lower (seventh) in the urban community. In addition to the high prevalence of smoking reported in the rural study population, reported alcohol use ranked second in the rural study population (80.0 rural vs. $54.2 \%$ urban, $P<0.01$ ). The recent South African Demographic and Health Survey (36) revealed a slight increase in the national prevalence of men consuming alcohol from 58 (1998) to 61\% (2016), while the prevalence among women remained unchanged (26\%).

In the present study, high blood pressure ranked among the top three risk factors in both communities, with prevalence levels of 67.9 and $56.9 \%$ among rural and urban participants, respectively. High prevalence of hypertension was also observed in the South African leg of the Prospective Urban Rural Epidemiological (PURE) Study (37), where a slightly higher prevalence of hypertension was seen in their urban (74.0) vs. rural (71.8\%) study population. Concerning results of the South Africa Demographic and Health Survey (SADHS) $(36,38)$ indicated that of the $46 \%$ South African women and $44 \%$ men who had hypertension, more than $80 \%$ of women and $87 \%$ of men presented with uncontrolled hypertension. Although 11.0 and 7.4\% (rural and urban participants, respectively) in the current study reported being diagnosed with diabetes, elevated $\mathrm{HbA1c}$, levels that provide a longer-term view of glycemic status, was observed in 9.7 rural vs. $6.0 \%$ urban participants. These results reflect poorly controlled or undiagnosed diabetes.

A high prevalence of overweight/obesity and waist circumference is linked to the high prevalence of metabolic disorders such as hypertension and type 2 diabetes mellitus (29). In both the study populations of the current study, overweight/obesity ranked fourth and sixth among the 10 behavioral and biological/metabolic risk factors observed in this study. More than half of rural and urban participants (53.2 and 54.2\%) were either overweight or obese and 59.1\% of rural participants (20.3 men vs. $75.5 \%$ women) and $53.4 \%$ of urban participants (6.0 men vs. $68.0 \%$ women) had waist circumference levels above the cut-off values. The prevalence of overweight or obesity among females living in urban and rural settings (66.1 and 65.6\%, respectively) in this study corresponds with findings of the SADHS (36) that reported that 68.4 and $66.1 \%$ females, living in urban and rural settings respectively, were either overweight or obese. In the current study, as in other South African surveys $(29,36)$, the prevalence of overweight and obesity was much lower among men than women.

Obesity is associated with chronic low-grade inflammation, and markers of inflammation such as CRP, TNF- $\alpha$, and IL-6 have been reported to correlate positively with adipocyte size (39). Lifestyle-related risk factors such as physical inactivity, poor diet and emotional stress are considered to be triggers that can cause activation of the immune system and consequently the hypothalamic pituitary adrenal stress response system, increasing the risk for obesity and chronic diseases such as CVD and diabetes mellitus $(8,11,40,41)$. This study confirmed a high prevalence of inflammation in both urban and rural participants that could be attributed to the higher cumulative risk effects of multiple risk factors. More than half of both urban and rural participants had five or more risk factors present for CDL. Almost $90 \%$ of rural participants had high HsCRP levels that have been associated with lifestyle risk factors such as smoking and physical inactivity (42) and correlate positively with BMI (43). Significant differences $(P<0.01)$ were observed between the study populations for the following inflammatory markers; total leucocytes levels (13.1\% rural vs. $4.3 \%$ urban), lymphocytes (7.7\% rural vs. $1.7 \%$ urban) and fibrinogen (32.9\% rural vs. $48.3 \%$ urban). An elevated leucocyte count is a strong independent risk factor for coronary heart disease morbidity and mortality, while NLR can also be used as a predicative tool for adverse cardiac events in diabetic patients with CVDs (44). Elevated fibrinogen levels were the highest-ranked inflammatory marker in both communities. The Emerging Risk Factors Collaboration group (45), investigated the value of CRP or fibrinogen in CVD prediction and found that one additional CDV event over a period of 10 years could be prevented with additional assessment of CRP or fibrinogen in patients at intermediate risk for a $\mathrm{CDV}$ event after initial screening of conventional risk factors. Chen and Lacey (7) used CRP and fibrinogen to indicate adult inflammation in a 1958 British birth cohort and illustrated that adverse childhood experiences, related to socio-economic and health behavioral factors, were associated with inflammation in mid-life.

In a community-based study in Shanghai, Zhang et al. (46) reported that hypertension, diabetes, and dyslipidemia were positively associated with obesity. In our study, multivariate logistic regression analysis revealed that in both the rural and urban sample, obesity was also associated with having hypertension. In addition, obesity was positively associated with 
being female and elevated fibrinogen levels. In the rural sample, obesity also increased the odds of having increased triglyceride and Hs-CRP levels, while in the urban sample, high blood glucose was positively associated with obesity. A communitybased cross-sectional Ethiopian study (47), reported that obesity was positively associated with daily intake of alcohol; while our study found that former and current smoking was negatively associated with obesity in both the urban (OR 0.42; $P<0.01$ ) and rural (OR $0.25 ; P<0.01$ ) study populations.

In terms of hypertension, multivariate logistic regression analysis showed that age advancement was more likely to be associated with the presence of hypertension in both rural and urban areas; a finding also observed in the earlier South African Adult Demographic and Health Survey (48) and a recent African based study (49). In addition, we found that the probability of having hypertension in the rural area was higher with increased reported stress levels, while high $\mathrm{HbAlc}$ levels increased the odds of having hypertension 10.40 (95\% CI 1.37; 78.98) times. The current study also found that increased waist circumference and $\mathrm{BMI} \geq 25.0 \mathrm{~kg} / \mathrm{m}^{2}$ were positively associated with the presence of hypertension. Similar observations were made by Zekewos et al. (49) who reported that age advancement, BMI $\left(\geq 25.0 \mathrm{~kg} / \mathrm{m}^{2}\right)$, and central obesity (waist-to-height ratio $\geq 0.50$ ) were positively associated with hypertension. Mbouemboue and Ngoufack (50) also reported that in a low-resource African setting, age, overweight and high serum triglyceride level were identified as independent factors predicting hypertension. The observation of Mahmood et al. (51) that in addition to age, education was an independent risk factor of hypertension for urban participants living in India, was not confirmed in the current study; however, adults residing in a rural area, with higher education levels were three times more likely to have CVDs; this can possibly be attributed to higher employment and income levels that can lead to unhealthy eating habits due to a higher intake of fast foods (6). Urban participants with hypertension (OR 2.84, 95\% CI 1.39; 5.78), high glucose levels (OR 2.24, 95\% CI $1.03 ; 4.88$ ), and elevated leucocytes (OR 3.17, 95\% CI 1.09; 9.21) were more likely to have CVDs. The logistic regression related to CVD and stress delivered unexpected results. The authors acknowledge that categorizing stress as "never," "few periods," and "several periods" may have been confusing to participants. Answers to questions related to concrete variables such as age and level of education are more easily answered by participants than variables that are more fluid, such as one's experience of stress.

In terms of diabetes, for participants living in a rural area, being physically inactive, having increased waist circumference, elevated triglycerides and leucocytes levels emerged as important associated risk factors of diabetes, while in an urban area advanced age was associated with diabetes. Vijayakumar et al. (52) reported that advanced age and the presence of central obesity were important risk factors for type 2 diabetes mellitus in an Indian study. As part of lifestyle management, the American Diabetes Association (ADA) (53) recommends focused goalbased behavioral lifestyle intervention programs for prediabetes patients, that includes 7\% weight loss and physical activity (150 min of physical activity, similar in intensity to brisk walking, per week).
Many governments are not keeping pace with the growing burden of lifestyle-related chronic diseases and associated demands on health services. Baird et al. (54) and Mikkelsen et al. (55) have emphasized the importance of adopting a life course approach that recognizes the opportunity to promote health, prevent and control NCDs at key stages throughout the life course, from preconception through to adulthood. Focusing on key life stages throughout the life course of the individual and implementing targeted lifestyle modifications and awareness programs can reduce the prevalence of prioritized risk factors for communities identified in this study, and break the risk cycle and the current intergenerational transmission of CDL in communities.

The authors acknowledge the following limitations of the study. Firstly, more females than males participated in the study, mostly because more males are employed laborers and therefore not available to participate on weekdays that the study was conducted and therefore, we acknowledge that the study population was not completely representative of the target population. We further acknowledge that not all relevant psychosocial factors (e.g., household composition, social support, depressive symptoms) were assessed or reported on in this publication. The exclusion of participants due to missing values occurred and is acknowledge by the authors as a limitation of the study, furthermore, we acknowledge that multiple testing took place due to the numerous variables involved and spurious results may occur.

\section{CONCLUSION AND RECOMMENDATIONS}

This study aimed to provide a better understanding of the health needs of urban and rural communities in the Free State with the aim of contributing to focused, targeted primary health care prevention and intervention programs for CDL, supporting the vision of the NDP to reduce the prevalence of chronic diseases in South African communities. The WHO has emphasized the importance of developing a holistic, integrated approach that targets the major common risk factors for CDL in the most cost-effective way to prevent and control CDL in communities.

Various studies have confirmed that a healthy lifestyle is associated with lower concentrations of inflammatory markers. Gaesser et al. (13) indicated that exercise and dietary factors, including dietary fiber, fruits (especially berries), omega-3 unsaturated fatty acids, antioxidant vitamins $\mathrm{E}$ and $\mathrm{C}$ and zinc could reduce inflammatory markers. Johannsen et al. (39) found that aerobic exercise not only reduced total WBC and neutrophil count in a group of overweight/obese women, but was particularly beneficial for those with low-grade systemic inflammation.

Based on the findings of this study, the researchers recommend:

- Focused and tailor-made community-based primary health care prevention [that include early screening toolkits and important point of care devices that can contribute to immediate identification of critical biochemical markers (HbAlc, Hs-CRP, fibrinogen)] and intervention programs that 
prioritize the identified multi-factorial etiology of CDL and related health needs in the different communities.

- Using the proposed approach to strengthen health and wellness educational programs in the different communities, with emphasis on the benefits of a healthy early environment and anti-inflammatory lifestyle throughout the individual's life course.

- Incorporating the following essential components in community-based chronic disease learning modules for undergraduate Health Professions programs:

- Contextual understanding of the multi-factorial etiology of CDL in different communities with emphasis on the different determinants (social, cultural, behavioral, biological, psychological, economic, and environmental) that drive $\mathrm{CDL}$ disease processes, at individual and collective levels in the communities.

- Promote a holistic integrated primary health care approach that focuses on the complementary roles of different health professionals involved in the care of patients with CDL in order to reduce the prevalence and associated prioritized risk factors of these diseases in the communities.

\section{DATA AVAILABILITY STATEMENT}

The raw data supporting the conclusions of this article will be made available by the authors, without undue reservation.

\section{REFERENCES}

1. World Health Organization (WHO). Non-communicable diseases [Internet]. Geneva (2018). Available online at: https://www.who.int/en/news-room/factsheets/detail/noncommunicable-diseases (accessed May 27, 2020).

2. Foreman KJ, Marquez N, Dolgert A, Fukutaki K, Fullman N, McGaughey M, et al. Forecasting life expectancy, years of life lost, and all-cause and causespecific mortality for 250 causes of death: reference and alternative scenarios for 2016-40 for 195 countries and territories. Lancet. (2018) 392:2052-90. doi: 10.1016/S0140-6736(18)31694-5

3. World Health Organization (WHO). WHO global health estimates 2016: deaths by cause, Age, Sex, by country and by region, 2000-2016 [Internet]. Geneva (2018). Available online at: https://www.who.int/healthinfo/global_ burden_disease/estimates/en/index1.html (accessed May 27, 2020).

4. Bennett JM, Reeves G, Billman GE, Sturmberg JP. Inflammation-nature's way to efficiently respond to all types of challenges: implications for understanding and managing "the epidemic" of chronic diseases. Front Med. (2018) 5:316. doi: 10.3389/fmed.2018.00316

5. Mayosi BM, Flisher AJ, Lalloo UG, Sitas F, Tollman SM, Bradshaw D. The burden of non-communicable diseases in South Africa. Lancet. (2009) 374:934-47. doi: 10.1016/S0140-6736(09)61087-4

6. Steyn NP, Labadarios D, Nel JH. Factors which influence the consumption of street foods and fast foods in South Africa-a national survey. Nutr J. (2011) 10:104. doi: 10.1186/1475-2891-10-104

7. Chen M, Lacey RE. Adverse childhood experiences and adult inflammation: findings from the 1958 birth cohort. Brain Behav Immun. (2018) 69:582-90. doi: 10.1016/j.bbi.2018.02.007

8. Barbaresko J, Koch M, Schulze MB, Nöthlings U. Dietary pattern analysis and biomarkers of low-grade inflammation: a systematic literature review. Nutr Rev. (2013) 71:511-27. doi: 10.1111/nure.12035

\section{ETHICS STATEMENT}

The studies involving human participants were reviewed and approved by Ethics Committee of the Faculty of Health Sciences (UFS-ETOVS number 21/07) Health Sciences Research Ethics Committee (HSREC) of UFS (UFS-HSD2017/1435). The patients/participants provided their written informed consent to participate in this study.

\section{AUTHOR CONTRIBUTIONS}

SZ were also responsible for the protocol and manuscript preparation, data collection, and data interpretation. GJ and FR were responsible for the data analysis. CW was the principle investigator. All authors were involved in the protocol and publication planning, writing, editing, and finalization.

\section{FUNDING}

The National Research Foundation was thanked for their financial support of this project.

\section{ACKNOWLEDGMENTS}

The research group gratefully acknowledges the contribution of the communities that participated in this study. The medical writer, Ms. T Mulder, Faculty of Health Sciences, University of the Free State, is acknowledged for the technical and editorial preparation of the manuscript for publication.

9. Calder PC, Ahluwalia N, Albers R, Bosco N, Bourdet-Sicard R, Haller D, et al. A consideration of biomarkers to be used for evaluation of inflammation in human nutritional studies. Br J Nutr. (2013) 109 (Suppl 1):S1-34. doi: 10.1017/S0007114512005119

10. Estampador AC, Franks PW. Genetic and epigenetic catalysts in early-life programming of adult cardiometabolic disorders. Diabetes Metab Syndr Obes. (2014) 7:575-86. doi: 10.2147/DMSO.S51433

11. Bosma-den Boer MM, Van Wetten M-L, Pruimboom L. Chronic inflammatory diseases are stimulated by current lifestyle: how diet, stress levels and medication prevent our body from recovering. Nutr Metab (Lond). (2012) 9:32. doi: 10.1186/1743-7075-9-32

12. Rhen T, Cidlowski JA. Anti-inflammatory action of glucocorticoidsnew mechanisms for old drugs. $N$ Engl J Med. (2005) 353:1711-23. doi: 10.1056/NEJMra050541

13. Gaesser GA, Angadi SS, Ryan DM, Johnston CS. Lifestyle measures to reduce inflammation. Am J Lifestyle Med. (2012) 6:4-13. doi: $10.1177 / 1559827611411646$

14. Department of Health. Strategic Plan 2015/16-2019/20 A long and healthy life for all South Africans. Available online at: http://www.health.gov.za/ index.php/2014-03-17-09-09-38/strategic-documents/category/229-2015str (accessed May 08, 2019).

15. Mash B, Fairall L, Adejayan O, Ikpefan O, Kumari J, Mathee S, et al. A morbidity survey of south african primary care. PLoS ONE. (2012) 7:e32358. doi: 10.1371/journal.pone.0032358

16. Frary CD, Johnson RK. Energy. In: Mahan LK, Escott-Stump S, editors. Krause's Food, Nutrition and Diet Therapy. 11th ed. Philadelphia: Saunders (2004).

17. World Health Organization (WHO). Global Database on Body Mass Index, BMI classification [Internet]. Geneva (2006). Available online at: http://apps. who.int/bmi/index.jsp?introPage=intro_3.html (accessed May 27, 2020). 
18. World Health Organization (WHO). Waist circumference and waist-Hip ratio: report of a WHO expert consultation [Internet]. Geneva (2008). Available online at: https://apps.who.int/iris/ bitstream/handle/10665/44583/9789241501491_eng.pdf;jsessionid= D961239D259944D3E13149E1FE4D8B6F? sequence=1 (accessed May 27, 2020).

19. World Health Organization (WHO). Online Q $\triangleleft A$ on hypertension [Internet]. Geneva (2015). Available online at: https://www.who.int/features/qa/82/en/ (accessed May 27, 2020).

20. World Health Organization (WHO). Use of Glycated Haemoglobin (HbA1c) in the Diagnosis of Diabetes Mellitus [Internet]. Geneva (2011). Available online at: https://apps.who.int/iris/bitstream/handle/10665/70523/WHO_ NMH_CHP_CPM_11.1_eng.pdf?sequence=1\&isAllowed=y (accessed May 27, 2020).

21. American Diabetes Association. Classification and diagnosis of diabetes: standards of medical care in diabetes. Diabetes Care. (2019) 42(Suppl 1):S1328. doi: $10.2337 / \mathrm{dc} 19-\mathrm{S} 002$

22. Pearson TA, Mensah GA, Alexander RW, Anderson JL, Cannon RO, Criqui $\mathrm{M}$, et al. Markers of inflammation and cardiovascular disease: application to clinical and public health practice: a statement for healthcare professionals from the centers for disease control and prevention and the American Heart Association. Circulation. (2003). 107:499-511. doi: 10.1161/01.CIR.0000052939.59093.45

23. Ampath. Ampath desk reference: guide to laboratory tests. 2nd ed. Centurion: Ampath (2016). Available online at: https://www.ampath.co.za/pdfs/DeskReference-web.pdf (accessed May 26, 2020).

24. Forget P, Khalifa C, Defour J-P, Latinne D, Van Pel M-C, De Kock M. What is the normal value of the neutrophil-to-lymphocyte ratio? BMC Res Notes. (2017) 10:12. doi: 10.1186/s13104-016-2335-5

25. Statistics South Africa. Mortality and causes of death in South Africa, 2016: Findings from death notification. Pretoria (2018). Available online at: http:// www.statssa.gov.za/publications/P03093/P030932016.pdf (accessed May 08, 2019).

26. Stringhini S, Forrester TE, Plange-Rhule J, Lambert EV, Viswanathan B, Riesen $\mathrm{W}$, et al. The social patterning of risk factors for noncommunicable diseases in five countries: evidence from the modeling the epidemiologic transition study (METS). BMC Public Health. (2016) 16:956. doi: 10.1186/s12889-016-3589-5

27. Wells JC. The capacity-load model of non-communicable disease risk: understanding the effects of child malnutrition, ethnicity and the social determinants of health. Eur J Clin Nutr. (2018) 72:688-97. doi: 10.1038/s41430-018-0142-x

28. Gray A, Vawda Y. Health policy and legislation. In: Padarath A, Barron P, editors. South African Health Review 2017. Durban: Health Systems Trust (2017).

29. Shisana O, Labadarios D, Rehle T, Simbayi L, Zuma K, Dhansay A, et al. South African National Health and Nutrition Examination Survey (SANHANES-1). Cape Town: HSRC Press (2014).

30. Wu F, Guo Y, Chatterji S, Zheng Y, Naidoo N, Jiang Y, et al. Common risk factors for chronic non-communicable diseases among older adults in china, ghana, mexico, india, russia and south africa: the study on global ageing and adult health (SAGE) wave 1. BMC Public Health. (2015) 15:88. doi: 10.1186/s12889-015-1407-0

31. Walsh CM, van Rooyen FC. Household food security and hunger in rural and urban communities in the free state province, South Africa. Ecol Food Nutr. (2015) 54:118-37. doi: 10.1080/03670244.2014.964230

32. Maimela E. Alberts M, Modjadji SE, Choma SS, Dikotope SA, Ntuli TS, et al. The prevalence and determinants of chronic non-communicable disease risk factors amongst adults in the dikgale health demographic and surveillance system (HDSS) site, limpopo province of South Africa. PLoS ONE. (2016) 11:e0147926. doi: 10.1371/journal.pone.0147926

33. Tydeman-Edwards R, Van Rooyen FC, Walsh CM. Obesity, undernutrition and the double burden of malnutrition in the urban and rural southern free state, South Africa. Heliyon. (2018) 4:e00983. doi: 10.1016/j.heliyon.2018.e00983

34. Steyn NP, McHiza ZJ. Obesity and the nutrition transition in Sub-Saharan Africa. Ann N Y Acad Sci. (2014) 1311:88-101. doi: 10.1111/nyas.12433

35. Steyn K, Levitt NS. Health services research in South Africa for chronic diseases of lifestyle. In: Steyn K, Fourie J, Temple N, editors. Chronic diseases of lifestyle in South Africa: 1995-2005. Technical report. Cape Town: South African Medical Research Council (2006).

36. National Department of Health. Statistics South Africa (Stats SA), South African Medical Research Council (SAMRC), and ICF. 2019. South Africa Demographic and Health Survey 2016 [Internet]. Pretoria, South Africa, and Rockville, Maryland, USA: NDoH, Stats SA, SAMRC, and ICF (2018). Available online at: https://dhsprogram.com/pubs/pdf/FR337/FR337. pdf (accessed May 08, 2019).

37. Egbujie BA, Igumbor EU, Puoane T. A cross-sectional study of socioeconomic status and cardiovascular disease risk among participants in the prospective urban rural epidemiological (PURE) study. S Afr Med J. (2016) 106:900-6. doi: 10.7196/samj.2016.v106i9.10456

38. National Department of Health. Statistics South Africa (Stats SA), South African Medical Research Council (SAMRC), and ICF. South Africa Demographic and Health Survey 2016. Key Findings [Internet]. Pretoria, South Africa, and Rockville, Maryland, USA: NDoH, Stats SA, SAMRC, and ICF (2018). Available online at: https://dhsprogram.com/pubs/pdf/SR248/SR248. pdf (accessed May 08, 2019).

39. Johannsen NM, Swift DL, Johnson WD, Dixit VD, Earnest CP, Blair SN, et al. Effect of different doses of aerobic exercise on total white blood cell (WBC) and WBC subfraction number in postmenopausal women: results from DREW. PLoS ONE. (2012) 7:e31319. doi: 10.1371/journal.pone.0031319

40. Pereira MA, Swain J, Goldfine AB, Rifai N, Ludwig DS. Effects of a lowglycemic load diet on resting energy expenditure and heart disease risk factors during weight loss. JAMA. (2004) 292:2482-90. doi: 10.1001/jama.292.20.2482

41. Liu S, Willett WC, Stampfer MJ, Hu FB, Franz M, Sampson L, et al. A prospective study of dietary glycemic load, carbohydrate intake, and risk of coronary heart disease in US women. Am J Clin Nutr. (2000) 71:1455-61. doi: 10.1093/ajcn/71.6.1455

42. Mazurek KL, Zmijewski P, Czajkowska A, Lutosławska G. High-sensitivity creactive protein (hscrp) in young adults: relation to aerobic capacity, physical activity and risk factors for cardiovascular diseases. Biol Sport. (2011) 28:22732. doi: $10.5604 / 965482$

43. Zarzour W, Dehneh N, Rajab M. High-sensitive c-reactive protein levels in a group of syrian university male students and its associations with smoking, physical activity, anthropometric measurements, and some hematologic inflammation biomarkers. Int J Inflam. (2017) 2017:7326527. doi: 10.1155/2017/7326527

44. Azab B, Chainani V, Shah N, McGinn JT. Neutrophil-lymphocyte ratio as a predictor of major adverse cardiac events among diabetic population: a 4-year follow-up study. Angiology. (2013) 64:456-65. doi: $10.1177 / 0003319712455216$

45. Emerging Risk Factors Collaboration, Kaptoge S, Di Angelantonio ED, Pennells L, Wood AM, White IR, et al. C-reactive protein, fibrinogen, and cardiovascular disease prediction. N Engl J Med. (2012) 367:1310-20. doi: 10.1056/NEJMoa1107477

46. Zhang Y, Gu Y, Wang N, Qi Z, Ng N, Wang R, et al. Association between anthropometric indicators of obesity and cardiovascular risk factors among adults in Shanghai, China. BMC Public Health. (2019) 19:1035. doi: 10.1186/s12889-019-7366-0

47. Mekonnen T, Animaw W, Seyum Y. Overweight/obesity among adults in north-western ethiopia: a community-based cross-sectional study. Arch Public Health. (2018) 76:18. doi: 10.1186/s13690-018-0262-8

48. Norman R, Bradshaw D, Steyn K. Chronic diseases, risk factors and lifestyles based on the South African adult demographic and health survey. In: Bradshaw, D, Steyn K, editors. Poverty and chronic diseases in South Africa. Tygerberg: Burden of Diseases Research Unit (2001).

49. Zekewos A, Egeno T, Loha E. The magnitude of hypertension and its risk factors in southern Ethiopia: a community based study. PLoS ONE. (2019) 14:e0221726. doi: 10.1371/journal.pone.0221726

50. Mbouemboue OP, Ngoufack TJ. High blood pressure prevalence, awareness, control, and associated factors in a low-resource african setting. Front Cardiovasc Med. (2019) 6:119. doi: 10.3389/fcrm.2019.00119

51. Mahmood SE, Ahmad A, Kashyap S. Prevalence and predictors of hypertension among adults of urban Lucknow, India: a community-based study. Heart India. (2019) 7:43-8. doi: 10.4103/heartindia.heartindia_6_19

52. Vijayakumar G, Manghat S, Vijayakumar R, Simon L, Scaria LM, Vijayakumar $\mathrm{A}$, et al. Incidence of type 2 diabetes mellitus and prediabetes in kerala, india: 
results from a 10-year prospective cohort. BMC Public Health. (2019)19:140. doi: 10.1186/s12889-019-6445-6

53. American Diabetes Association. prevention or delay of type 2 diabetes: standards of medical care in diabetes. Diabetes Care. (2019) 42:S29-33. doi: $10.2337 / \mathrm{dc} 19-\mathrm{S} 003$

54. Baird J, Jacob C, Barker M, Fall CH, Hanson M, Harvey NC, et al. Developmental origins of health and disease: a lifecourse approach to the prevention of non-communicable diseases. Healthcare (Basel). (2017) 5:14. doi: 10.3390/healthcare5010014

55. Mikkelsen B, Williams J, Rakovac I, Wickramasinghe K, Hennis A, Shin H-R, et al. Life course approach to prevention and control of non-communicable diseases. BMJ. (2019) 364:1257. doi: 10.1136/bmj.1257
Conflict of Interest: The authors declare that the research was conducted in the absence of any commercial or financial relationships that could be construed as a potential conflict of interest.

Copyright (c) 2020 van Zyl, van Rooyen, Joubert, Kruger and Walsh. This is an open-access article distributed under the terms of the Creative Commons Attribution License (CC BY). The use, distribution or reproduction in other forums is permitted, provided the original author(s) and the copyright owner(s) are credited and that the original publication in this journal is cited, in accordance with accepted academic practice. No use, distribution or reproduction is permitted which does not comply with these terms. 